\title{
The Global Aspects of Modern Media Education in Educational Space
}

\author{
Veronica Yarnykh \\ Russian State University for Humanities, Moscow, Russian Federation
}

\begin{abstract}
The modern world cannot be imagined without media products. We use media in everyday life in communications, in social and economic life, and in the educational space. The educational space and the role of the educator of any level have changed significantly and is changing at the present moment. Technologies and training tools should meet the needs of stakeholders and be relevant for all representatives of all generations in society. Media education is a multi-disciplinary and global direction in modern pedagogy. The development of this direction in the educational space is influenced by many global factors, including digital technologies, convergence in media education, media didactics, and new global media competencies in the professional competency profile.
\end{abstract}

Keywords: media education, convergence of media education, media competency, media competencies

\section{Introduction}

It is difficult to imagine modern life without media. It is impossible to over-estimate the importance of media in contemporary social life and in the social and economic information sphere. No less important is the media in the modern educational space.

A fundamental change in the learning paradigm, changes in the profile of professional competences, changes in the educational space in connection with the emergence of a fundamentally new generation of $\mathrm{Z}$-all this has a strong influence on the educational space in general, and on media education in particular. It should be noted that there is no precise definition of the sphere of media education at the moment.

\section{Global Meanings of Media Education}

The developing of meaning of media education in historic perspective is interesting. In the Czech and German context, this is also associated with the introduction of innovative spelling-book from John Amos Comenius to Latin education at schools as noted (Masek \& Sloboda, 2010). Also, the first consideration that people should learn to live with the media comes from the early 17th century, again from the "teacher of nations.” And in the writing book also form John Amos Comenius in 1650 (Masek \& Sloboda, 2010), it noted that schools should work with the newspapers.

Baake (1996) suggested the following definition with four main focuses: (a) knowing about different media and how to use them; (b) reflecting the role of media in society; (c) designing media; and (d) critical thinking.

Veronica Yarnykh, Ph.D., associate professor, head of Department of TV, Radio and Internet Communications, Faculty of Journalism, Russian State University for Humanities. 
As United Nations Educational, Scientific, and Cultural Organization (UNESCO) (2014) noticed at the heart of media and information literacy lain the need to empower citizens with essential knowledge about the functions of media and information systems in democratic societies, under what conditions these functions can be performed and how citizens can evaluate the quality of the content they provide. By bringing together the fields of media and information (M \& I) literacy, the literacy curriculum presents a holistic approach to literacy that is necessary for life and work today.

Therefore, it is possible to summary that there is no exact definition of media education, but there are many approaches from which the researches and educators explain the subject.

\section{Media Competence in Professional Educator's Profile}

For a modern teacher of any level, media competence becomes one of the basic competences in the professional profile. Many researchers identify the various professional competencies of educators related to the field of media. For example, Doug Johnson (2010) identified the following competencies:

1. Help students use educational networking tools to solve information problems and communicate digitally with experts, peers, and instructors;

2. Know the major Web 2.0 categories and tools that are useful in the kindergarten to Grade 12 (K-12) setting. Know which tools are provided/supported by one's school;

3. Use educational networking sites to communicate with teaching peers, students, and parents;

4. Navigate, evaluate, and create professional content on networking sites;

5. Use online networking to create, maintain, and learn from a personal learning network and their students;

6. Know the district networking guidelines, follow netiquette, conform to ethical standards, and interact appropriately with others, especially students online;

7. Understand copyright, security, and privacy issues on social media sites and share these understandings with students and professional colleagues;

8. Understand the importance of identity and reputation management using social media and help students understand the long-term impact of personal information shared online;

9. Create and follow a personal learning plan to stay informed about developing trends, tools, and applications of social media;

10. Participate in the formulation of school and district policies and guidelines related to educational networking and social learning.

As appears from the above, the inclusion in the profile of the teacher's professional competencies of knowledge, skills, and norms of behavior from the sphere of media education significantly changes not only his/her professional competence. The very understanding that media competence, along with information and media security, make up a rigid change in the requirements for the professional training of educators changes the approaches to his/her professional education.

If we analyze the carefully listed competencies, that is, the behavior patterns become absolutely clear and important. Also, the patterns of behavior and the role of the pedagogue in the society have changed significantly. It becomes important not just to use media products as such during the learning process. It is not enough to use electronic textbooks. And it is not enough to create media products in the framework of educational projects. It becomes fundamentally important to form a unified media and information educational 
space, where all participants use tools and technologies that are familiar to them. And if these tools are familiar to students or school children, unfortunately, they are not so familiar to educators.

In this case, UNESCO (2014) allocated the inter-disciplinary M \& I competencies for educators of any level, such as:

1. Definition and articulation of the information;

2. Location and access of the information;

3. Assessment of information;

4. Organization and use of the information;

5. Communication and ethical use of the information;

6. Understand the role and functions of media;

7. Understand the conditions under which media and fulfill there;

8. Critically analyze and evaluate media content;

9. Use of media for democratic participation, intercultural dialogue, and learning;

10. Produce user-generated content;

11. Informational and computer technologies (ICT) and other media skills.

So, we can see that from different ways and approaches researches and practices tell about competence in modern media world. As can be seen from the list of competences proposed by UNESCO, the creation of the actual content by users, that is, students and educators as a whole is a mandatory requirement. And in this regard, it becomes important to note one of the approaches to understanding media education and media didactics.

Jennifer Tiede, Silke Grafe, and Renee Hobbs (2015) noted that media pedagogical competences were defined as the interaction of the three areas, namely: (a) media didactics (the use of the mass media to promote and support learning processes); (b) media education (when the related media education and training objectives); and (c) school development (use of mass media for the problems associated with the development of educational institutions).

It is necessary to pay attention to the fact that in this case, we are talking about media didactics and media education, but the third component is the practice in the development of the organization. And here, it is important to note the inclusion in modern media education of such a concept as corporate communications. In fact, in this case, we are talking about the participation of teachers in the representation and development of media corporate communications. In this case, the representation of the educational organization in the media is the task not only of media and public relations (PR) specialists, but also the teachers themselves. And the educational media products, and even personal media products of the modern teacher form the corporate image of the educational organization.

\section{Media Education in Modern Educational Space}

Such a multi-disciplinary and multi-functional approach allows us to take a new look at the role of media education in the modern educational space.

Also, these researchers allocate that each of these areas is further divided into five qualification aspects, including:

1. The understanding and assessment of conditions;

2. The description and assessment of theoretical approaches; 
3. The analysis and evaluation of relevant studies and expertise;

4. The development of proposals on the basis of its own theoretical framework;

5. The implementation and evaluation of the theory on the basis of practical examples.

Thus, as it can be seen from the proposed approach, the role of the practical component essentially increases. The use of real cases, practices, and expertise, in this case, makes it possible to broaden the understanding and scope of media didactics as such, for example. Also, in the proposed approach, an extended relationship between theoretical approaches and real practice of media communications is present and proposed. This forms the possibility of considering media didactics and media education as a whole as a convergent approach.

In this case, it is possible to say that media education in modern educational space has several areas of application and development. This is a professional media education for journalists, PR specialists, etc.. This is the direction of media education and training of media security in general for all comers. And, finally, this use of the media education tools in educational space. By analogy with modern media approaches, we can talk about the convergence of media education in general, and in particular, the convergent approach to media education in the educational space. Such diversity in the field of media education, on the one hand, makes it possible to widely use various tools and technologies of media education in various fields, on the other hand, it has the flexibility and the ability to adapt to a changing world around.

It is necessary to draw special attention to the notion of convergence in media education. As Stavroula Kaloregas (2013) noted media convergence could be categorized as follows:

1. Technological convergence- the digitization of all media content which allows them to flow across platforms;

2. Economic convergence- - the horizontal integration of the entertainment industry;

3. Social convergence-consumers are multi-tasking and navigating through the new media rich environments;

4. Cultural convergence - the rise of a new participatory culture by giving the average person the tools needed to recreate and recirculate content;

5. Global convergence-the crossbreed of culture that results from a plethora of media content. And finally, as she suggests educational;

6. Informational convergence-the distance learning paradigm, which is influencing and changing the traditional methods of teaching and learning.

It is the formation of such a convergent approach in modern media education of different directions that allows us to take a fresh look at the situation. As a result of media convergence, new theoretical approaches and technologies of media education are emerging and expanding. Here, you can note that the distance education, e-learning, and other ones. Expanding the use of media tools in the educational space allows the most accurate response to the needs of stakeholders in the modern educational space.

This is one of the understandings of the media education course. However, it should be noted that in the context of the development of convergent media education, one of the main tasks of the educator is the formation of a single media and communication space. Various educational organizations of different levels, including secondary and tertiary education, use various media resources and media technologies for this. Also, convergence in media education allows taking into account the request for educational tasks of generation $\mathrm{Z}$, a new generation of students in educational organizations of any level. 
Among media tools and technologies, the following can be noted which can be used or which are already in use:

1. Implementation of real media projects of the training system;

2. Massive open online courses (MOOC) for additional tools and materials for making the whole educational space, for discussion and communication;

3. The formation of unified educational and media space for groups of participants. In practice, groups used social networks and messengers. This allows for including the possibility of mutual consultation of program participants. It could be also the internal corporate communication tools of educational organizations;

4. The master-classes of successful participants with the idea of best practices;

5. The use of multi-media resources in the learning process with different tasks and results;

6. The use of case - study, modeling and other innovative technologies in teaching practice;

7. The use of digital practice and expertise as electronic textbooks etc..

8. The use digital formats for presentation educational materials;

9. New media opportunities for project activity in different level of education.

Among them, they are as methods of technical support, but also the methods of communication, presentation, and discussion.

The wide use of modern media products, the inclusion of media resources in the educational process, the formation of a single communication media space allows us to use the tools of communication and communication familiar to this generation.

There are many works and researches about new generation Z. According to the analysis (Ford, 2015), these employees preferred a digital lifestyle, which meant that they felt comfortable in a multi-tasking situation, but did not necessarily communicate well in the society. Some researchers believe that representatives of the generation $\mathrm{Z}$ have short intervals of attention, which is easier to attract, often changing approaches. It was also found that in the educational space these students would not tolerate the form of training "wise man on the stage” and easily interact with teachers as facilitators. This is true for business. Representatives of these generations have a high ability of independent learning and critical thinking, but only when they feel that knowledge is important or valuable. They prefer active learning and a student-centered learning environment. Students of generation $\mathrm{Z}$ refer to gadgets every seven minutes. Therefore, the use of the usual communication channels in the communication process gives a good result.

Now, employees want to communicate with the messenger instead of going to the executive's office during working hours, they need films not novels. This new generation wants to be creative and critical about problems, but only if they can see the relevance of the subject, the use of learning outcomes in everyday life. They succeed in the relevant knowledge and prefer active learning or project tasks. Employees from generation $\mathrm{Y}$ are not afraid of risks and often confidently use new ideas and technologies. Employees of generation $\mathrm{Z}$ do not have the same confidence. Representatives of the generation $\mathrm{Z}$ grew up with technology in their hands, and most of them had access to high-speed Internet connections for most of their life. The speed at which they can access digital tools and the knowledge they need is important to them. For slow solutions and technology, they lack patience. They expect that they will be able to quickly find the information they need and are often disappointed if the solution is not so easy to find.

Such requirements substantially change the information and communication space of any organization. Information technology (IT) and Hi-tech business faced this challenge earlier, due to the massive arrival of 
representatives of the generations of $\mathrm{Y}$ and $\mathrm{Z}$ as employees. And their expertise and experience make it possible to build communication communications efficiently both inside the company and with clients.

Also, for example, Kaylynn Chong (2017) noticed that generation Z had several features, which made them different from other generations. They lead secret live, they are resistant to advertising, they are easily bored, and they want to be engaged. It means that for this generation it is necessary to find absolutely another way of studying and learning. Even student (pupil)-centered education is not enough now. It is too boring for them.

Creating your own content, discussing possibilities, searching for information, playing and storytelling, and maximizing your own thoughts and achievements become important to them. Of course, it creates another problem, because it is impossible to play all the time in training. As it is impossible to make all topics in the course as exciting and interesting as possible. Something will certainly remain boring.

The school teachers were the first to encounter this problem. Generation $\mathrm{Z}$ came to school and it turned out that media education for teachers of schools and colleges is extremely in demand. A new generation of students lives in a different reality, they do not just use gadgets, and they live in a new reality. And they want to see their usual reality in the classroom. And if in schools, due to the age of the students, it is possible to use gamification, storytelling, media products, and new reality quite widely, then in high school, it is somewhat difficult. And now, this generation comes into the system of higher education and as it turns out the generation of teachers of higher education is not ready to meet with them.

It was very interesting to trace the change in the subject of final qualification works at the Faculty of Journalism of the Russian State University for Humanities (Moscow) for the last three years (2014-2016). During this time, approximately the same number of students was graduated on the profile of "TV-journalism." Each year, the output was about 60 people.

The dynamics of the topic of works connected in one form or another with new media and modern media products was increased from $17 \%$ (2014) to $65 \%$ (2016). This is an indicator of changing preferences and society, students, and employers. And do not notice this dynamic is impossible. It is necessary to evaluate as accurately as possible the need to change the training and retraining of teachers themselves at any level. As in higher education, and at other levels of education.

In this regard, it is necessary to return to the approach of UNESCO, which combined approaches to media and information literacy and security in a unified approach. Information and digital technologies do not just come into our lives, affecting any of the generations. They become in many ways our real life, introducing massively new virtual and technical capabilities.

In the society, there were fundamental changes, largely caused by digital technologies. These global opportunities have fundamentally changed and continue to change the educational space. It becomes not just global in all senses. The profession of the teacher becomes global and in essence and on approaches.

\section{Conclusions}

In conclusion, it should be noted that modern media education at different levels and in different spheres is in a state of development. Within the media didactics at the moment, there are no unambiguous interpretations and formulations. Within the framework of media education, there are several approaches and opportunities for development. Media education is closely connected with modern digital, communication and information technologies, and this approach has been suggested from the point of view of UNESCO as media and 
information and computer technologies (M \& ICT) literacy. Media education in the modern educational space is a global approach and global factors of influence.

Among the global factors of influence, there is a fundamental change in the role of the educator in the educational space, including the inclusion of media competences in the professional profile of the teacher's competencies, and the active global influence of the generation $\mathrm{Z}$ on the modern educational process precisely from the point of view of media education.

Thus, it is precisely in the global approach and communication, the influence of global factors on the development of media education that this approach has a certain potential for the development of modern media education at any level.

\section{References}

Baacke, D. (1996). Media competency as a network: Reach and focus on a concept that has economic activity. Virtually Media in Media Practice, 20(78), 4-10.

Chong, K. (2017). The social media habits of generation Z. Retrieved August 15, 2017, from https://www.blog.hootsuite.com/ social-media-gen-z/

Ford, T. (2015). Five tips for teaching generation Z in college. Retrieved August 15, 2017, from https://www.blog.tophat.com/ generation- $\mathrm{z} / \mathrm{html}$

Johnson, D. (2010). Top ten social media competences for teachers. Retrieved August 15, 2017, from http://www.doug-johnson. squarespace.com/blue-skunk-blog/2010/7/31/top-ten-social-media-competencies-for-teachers.html

Kalogeras, S. (2013). Media-education convergence: Applying trans-media storytelling edutainment in e-learning environments. International Journal of Information and Communication Technology Education, 9(2), 1-11.

Masek, J., \& Sloboda, Z. (2010). Media pedagogics: An innovative sub-discipline of Czech educational sciences? Retrieved August 17, 2017, from http://www.medialnipedagogika.cz/wp-content/uploads/Masek_Sloboda_MedPed-in- Czech-Rep_ NEW.pdf

Tiede, J., Grafe, S., \& Hobbs, R. (2015). Pedagogical media competencies of pre-service teachers in Germany and the United States: A comparative analysis of theory and practice. Peabody Journal of Education, 90(4), 533-545.

United Nations Educational, Scientific, and Cultural Organization (UNESCO). (2014). Media and information literacy curriculum for teachers. Retrieved August 15, 2017, from http://www.unesco.org/new/fileadmin/MULTIMEDIA/HQ/CI/CI/pdf/media_ and_information_literacy_curriculum_for_teachers_en.pd 